\title{
SELF-CONSCIOUSNESS AND IMMUNITY*
}

$\mathrm{O}$ ne of the most seminal contributions to the understanding of self-consciousness over the last half century has been Sydney Shoemaker's articulation of the idea that we are "immune to error through misidentification relative to the firstperson pronouns" (IEM). Along with related ideas developed by Wittgenstein, Castenada, Evans, Perry, and Pryor, ${ }^{2}$ IEM has proven to be extremely fertile in stimulating insights into the first-person perspective, "the distinctive way mental states present themselves to the subjects whose states they are." ${ }^{3}$ Moreover, Shoemaker's formulation of the idea has motivated significant interdisciplinary research into self-consciousness. ${ }^{4}$

Since first formulating his position, Shoemaker has done much to elaborate upon IEM and related notions. For more than four decades he has been perspicaciously developing his ideas on identificationfreedom, introspection, self-knowledge, and the self-intimation of mental states. Although some aspects of Shoemaker's views on immunity have been disputed, IEM itself has never been severely threatened by any empirical challenge. ${ }^{5}$

\footnotetext{
* We are extremely grateful to Frédérique de Vignemont, Tim Bayne, Thomas Metzinger, Olaf Blanke, Shaun Gallagher, David Rosenthal, Valeria Petkova, several participants in the ASSC 13 Conference (in Berlin), and to this JOURNAL's anonymous referees for their helpful comments on previous versions of this manuscript. Work on this manuscript was, in part, funded by National Science Council of Taiwan research grants 97-2410-H-004-154-MY3 and 97-2410-H-002-184-MY3.

${ }^{1}$ Sydney Shoemaker, "Self-Reference and Self-Awareness," this JOURnAL, Lxv, 19 (October 3, 1968): 555-67. In previous work he had attempted to make a similar point by referring to certain self-ascriptions that are "noncriterial." See Shoemaker, Identity, Cause, and Mind (New York: Oxford, 2003), p. 2.

${ }^{2}$ See Ludwig Wittgenstein, The Blue and Brown Books (New York: Oxford, 1958). Also see Gareth Evans, The Varieties of Reference (New York: Oxford, 1982); James Pryor, "Immunity to Error through Misidentification," Philosophical Topics, xxvi, 1-2 (1999): 271-304; and additional representative works in Andrew Brook and Richard DeVidi, eds., Self-Reference and Self-Awareness (Philadelphia: John Benjamins, 2001).

${ }^{3}$ Shoemaker, The First-Person Perspective and Other Essays (Cambridge: MIT, 1996).

${ }^{4}$ See Jose Bermudez et al., eds., The Body and the Self (Cambridge: MIT, 1995); Bermudez, The Paradox of Self-Consciousness (Cambridge: MIT, 1998); and Masaharu Mizumoto and Masato Ishikawa, "Immunity to Error through Misidentification and the Bodily Illusion Experiment," Journal of Consciousness Studies, XII, 7 (2005): 3-19.

${ }^{5}$ For example: several essays in Brook and DeVidi, eds., op. cit.; Colin McGinn, The Subjective View (New York: Oxford, 1983), pp. 45-55; Evans, op. cit., pp. 188-91; and Bermudez, op. cit., pp. 6-8.
} 
Perhaps the most substantial empirical challenge thus far attempted has been Campbell's ${ }^{6}$ claim that schizophrenic thought insertions, understood in terms of the Frith ${ }^{7}$ monitoring model, might serve as a counterexample to IEM. Gallagher and Coliva have defended IEM by (among other things) arguing that since schizophrenic thoughts are still within a patient's stream of consciousness, IEM is not violated. ${ }^{8}$ They hold that, as a matter of conceptual truth, "if a subject is introspectively aware of a certain mental state, then she herself is having it and, therefore, that mental state is her own." 9

In this paper we argue that IEM fails. In section I, we adumbrate Shoemaker's version of IEM along with related concepts central to his understanding of self-consciousness. We also reject the interpretation of IEM as a tautology, and propose to treat it as a hypothesis. In section II, we present a clinical case-somatoparaphrenia-and in section III we describe an experiment with healthy subjects-the Body Swap Illusion. In the former case, patients represent experienced sensations as belonging to someone other than self. In the latter, an illusion is created whereby subjects feel that they can shake hands with themselves. The one concerns bodily sensations; the other, the sense of agency. ${ }^{10}$ Both cases reveal that IEM lacks modal force: what IEM says cannot happen, can happen. In section IV we respond to possible criticisms of our position. In a concluding section we emphasize that in order to account for the phenomena which seem to defy IEMbased expectations, there is a need to distinguish the ownership of mental states from the ownership of body parts. Moreover, concerning the former, there is a compelling need to distinguish between mental states that are instantiated and mental states that are represented as belonging to oneself.

\footnotetext{
${ }^{6}$ John Campbell, "Immunity to Error through Misidentification and the Meaning of a Referring Term," Philosophical Topics, xxvi, 1-2 (1999): 89-104.

${ }^{7}$ Christopher Frith, The Cognitive Neuropsychology of Schizophrenia (Hove, UK: Erlbaum, 1992).

${ }^{8}$ Shaun Gallagher, "Self-Reference and Schizophrenia: A Cognitive Model of Immunity to Error through Misidentification," in Dan Zahavi, ed., Exploring the Self: Philosophical and Psychological Perspectives on Self-Experience (Philadelphia: John Benjamins, 2000), pp. 203-39; Annalisa Coliva, "Thought Insertion and Immunity to Error through Misidentification," Philosophy, Psychiatry and Psychology, Ix, 1 (2000): 27-34; and Coliva, "On What There Really Is to Our Notion of a Thought," Philosophy, Psychiatry and Psychology, Ix, 1 (March 2000): 41-46.

${ }^{9}$ Coliva, "Thought Insertion," p. 28.

${ }^{10}$ In this paper "the sense of agency" and "agency" are used interchangeably. Both terms refer to first-person, conscious experience. For recent discussion of "agentive experience" see Tim Bayne, "The Sense of Agency," in Fiona Macpherson, ed., The Senses (New York: Oxford, 2011). Also see below, note 63.
} 


\section{SHOEMAKER'S IMMUNITY PRINCIPLE}

In his reflections on self-consciousness, Shoemaker takes as a point of departure what he regards as an incontrovertible conceptual truth: "an experiencing is necessarily an experiencing by a subject of experience." ${ }^{11}$ He evinces that a subject and an experience are just as intimately related as are a branch and a branch-bending. He then proceeds to develop a conception of self-consciousness that aspires to compatibility with both naturalism and certain Cartesian intuitions.

Developing one among these intuitions, and taking his lead from Wittgenstein, Shoemaker marks a distinction between the use of "I" (and its cognates) "as subject" and its use "as object." 12 Use-as-subject refers to such expressions as "I am in pain"; use-as-object refers to such expressions as "I am bleeding." Imagine, for example, that a baserunner and a catcher collide at home plate. As is not uncommon, the catcher's leg is gashed by the spikes on the base-runner's shoes, although the catcher does not immediately feel any pain. Because their limbs are entangled, upon first seeing the wound, the catcher does not immediately recognize it as his. As they disentangle, and as the catcher notices distinguishing features like the differences in their uniforms, he comes to realize that it is he who is bleeding. Recognition from the outside, so to speak, as in identifying the source of the bleeding, is recognition of self-as-object. The experience of pain, by contrast, given that it is known through introspection, typifies knowing about the self "as subject."

Wittgenstein's guiding intuition, one which is endorsed by Shoemaker, is: "...there is no question of recognizing a person when I say I have tooth-ache $[s i c]$. To ask 'are you sure it is you who have pains?' would be nonsensical."13 Shoemaker identifies the following as prototypical expressions of self-as-subject: "I feel pain"; "I am waving my arm"; and "I see a canary." Clearly he believes that his argument is applicable to bodily sensation, to the sense of agency, and to perception of the external world. Take "I see a canary," for example: I might be mistaken concerning what I actually see (it might be a cardinal). I might even

\footnotetext{
${ }^{11}$ Shoemaker, First-Person Perspective, p. 10.

${ }^{12}$ Shoemaker, "Self-Reference and Self-Awareness"; Wittgenstein, op. cit., pp. 66-67.

${ }^{13}$ Shoemaker, "Self-Reference and Self-Awareness," p. 556.

${ }^{14}$ Ibid., pp. 557-58. These three prototypical cases are all mental states that Shoemaker elsewhere describes as "weakly self-intimating": that is to say, it is the nature of these mental states to intimate themselves to their "possessors." Cf. Shoemaker, First-Person Perspective, pp. 50-52. Shoemaker adds that self-reference of this sort is not restricted to first-person pronouns: names and definite descriptions can self-refer in comparable ways. See Shoemaker, "Persons and Their Pasts," American Philosophical Quarterly, viI, 4 (October 1970): 269-85. The relevant discussion appears in footnotes 3 and 5. Also see Shoemaker, Identity, Cause, and Mind, p. 10, fn. 4.
} 
be hallucinating. But "it cannot happen that I am mistaken in saying this because I have misidentified as myself the person I know to see the canary." 15

Why should it be nonsensical to query whether one is certain that it is oneself who is experiencing the mental state? Because, Shoemaker maintains, when we make a judgment like "I feel pain," we are aware that "one does, oneself, feel pain...one is, tautologically, aware, not simply that the attribute feel(s) pain is instantiated, but that it is instantiated in oneself." 16 Accordingly, it simply "cannot happen that I am mistaken in saying 'I feel pain' because, although I do know of someone that feels pain, I am mistaken in thinking that person to be myself."17 The same is true for judgments about hand-waving or seeing canaries. Notice that these cases exude the modal force of "cannot." According to Shoemaker this is what makes self-consciousness special.

Shoemaker further elucidates IEM. He says that to claim that a statement " $a$ is $\Phi$ " might be erroneous through misidentification relative to the term " $a$ " is to allow for the following possibility: "the speaker knows some particular thing to be $\Phi$, but makes the mistake of asserting ' $a$ is $\Phi$ ' because, and only because, he mistakenly thinks that the thing he knows to be $\Phi$ is what ' $a$ ' refers to." 18 But for IEM statements, mistakes of this type are not possible. If the ground of my judgment is introspection, ${ }^{19}$ whenever I say "I feel pain" it cannot be the case that I am mistaken in thinking that the person in pain is me. Likewise, whenever I say "I am waving my arm" or "I see a canary" it cannot be the case that I have erroneously identified myself as the person who waves his arm or sees the canary.

How is it that immunity should obtain in such cases? Shoemaker replies that the relevant mental states are identification-free. He believes that even when we need to identify self (as-object), identification "will always presuppose the prior possession of other first-person information." ${ }^{20}$ If self-consciousness always involved identification, whenever

\footnotetext{
${ }^{15}$ Italics added by the authors. Shoemaker distinguishes between absolute and circumstantial immunity. Our concern throughout this paper is exclusively with absolute immunity as regards the self-attribution of mental states.

${ }^{16}$ Shoemaker, "Self-Reference and Self-Awareness," pp. 563-64.

${ }^{17}$ Ibid., p. 557. Also see Shoemaker, "Self-Knowledge and 'Inner Sense,' Lecture I: The Object Perception Model,” Philosophy and Phenomenological Research, LIV, 2 (June 1994): 249-69, at p. 258; Shoemaker, First-Person Perspective, p. 15.

${ }^{18}$ Shoemaker, "Self-Reference and Self-Awareness," p. 557. Here we are only concerned with present-tense statements, but Shoemaker claims that IEM also holds for certain memory judgments. See Shoemaker, "Persons and Their Pasts."

${ }^{19}$ Cf. Pryor, "Immunity to Error through Misidentification," p. 279; and Joel Smith, "Which Immunity to Error?" Philosophical Studies, Cxxx, 2 (August 2006): 273-83.

${ }^{20}$ Shoemaker, “Self-Knowledge and 'Inner Sense,' Lecture I,” p. 258.
} 
we self-ascribed a mental state (for example, " $a$ is $F$ ") we would need to establish both " $b$ is $F$ " and " $a=b$." But " $b$ is $F$," in turn, would further require that " $c$ is $F$ " and " $b=c$ " be established. To avoid an infinite regress, we must allow for first-person knowledge that is not grounded in an act of identification.

To illustrate this concern, consider the following. If I notice someone on a shopping center video display, I might wonder whether it is me. In order to make a proper identification, I might pull on my cap while checking to see whether the person on the video display does likewise. To perform this act of identification I must know that I myselfam pulling on my cap. How can I know that? According to Shoemaker, my firstperson knowledge that I am pulling on my cap must be grounded in identification-free first-person knowledge, because the only alternative would be just the sort of vicious infinite regress schematized above. ${ }^{21}$

Identification-freedom is also integrally related to his views on introspection, the self-intimating character of mental states, and the impossibility of self-blind creatures. For Shoemaker, introspective knowledge refers to just routine, mundane sorts of knowledge.$^{22}$ In his reflections on how best to understand introspection, he rejects "inner sense" models, notably the "object perception model" (OPM) and the "broad perceptual model" (BPM).

According to Shoemaker, if OPM is correct, then "identification information" about the perceived object must be available. ${ }^{23}$ Critically, these objects would need to be independent of acts of perception. But Shoemaker denies that there is any such role for awareness of selfas-object to play in the explanation of introspective knowledge. Although it might appear to be the case that self is a good candidate for being an object of perception, Shoemaker believes that when we do need to identify self-as-object, identification "will always presuppose the prior possession of other first-person information."24 Again, the only alternative to freedom from identification would be profligate identification, identification that cannot but lead to vicious infinite regress.

Shoemaker also rejects BPM, which differs from OPM in concerning itself with facts rather than objects. ${ }^{25}$ Despite this difference, though,

\footnotetext{
${ }^{21}$ Shoemaker, "Self-Reference and Self-Awareness," p. 561, and First-Person Perspective, p. 196.

22 "The knowledge I have in mind is...the humdrum kind of knowledge that is expressed in such remarks as 'It itches,' 'I'm hungry,' 'I don't want to,' and 'I'm bored.'” See Shoemaker, “Self-Knowledge and 'Inner Sense,' Lecture I,” p. 249.

${ }^{23}$ Ibid., pp. 252-53.

${ }^{24}$ Ibid., pp. 254, 258.

${ }^{25}$ Shoemaker, "Self-Knowledge and 'Inner Sense,' Lecture II: The Broad Perceptual Model,” Philosophy and Phenomenological Research, LIV, 2 (June 1994): 271-90.
} 
BPM shares a fundamental commitment to the view that in perception we have access to things that are independent of being perceived. So identification-freedom would be incompatible with this model too.

Shoemaker's rejection of BPM is also linked to his rejection of the possibility of "introspective self-blindness." He believes that a significantand unacceptable-consequence of BPM is that it allows for the logical possibility of this particular kind of blindness. ${ }^{26}$ To be introspectively selfblind with respect to certain kinds of mental phenomena would require that, despite being able to conceive of those phenomena (just as the blind can conceive of phenomena unseen), a creature would be unable to introspectively access them. According to Shoemaker, BPM is only worth taking seriously if self-blindness is regarded as a conceptual possibility. ${ }^{27}$ But he regards this notion to be as absurd as the claim that we could have pains but be systematically and blithely unaware of them. ${ }^{28}$

In short, in addition to IEM, Shoemaker endorses a "modest Cartesianism," a "weak version of the self-intimation thesis" (WST). On this view, the existence of certain mental entities is constitutively related to their being available to introspection. For those mental states that have phenomenal character, for example, it is of their essence that having them "issues in the subject's being introspectively aware of that character, or does so if the subject reflects." ${ }^{29}$ There might well be internal states to which we do not have introspective access, states that play an important role in causing behavior. But Shoemaker says such states would not count as mental. The proper way to think of the relationship between introspection and mental states is that "the reality known and the faculty for knowing it are...made for each other-neither could be what it is without the other." 30

Most philosophers regard IEM as a semantic or conceptual thesis. Recall that, according to Shoemaker, when one proclaims self to be in pain "one does, oneself, feel pain...one is, tautologically, aware, not simply that the attribute feel(s) pain is instantiated, but that it is instantiated in oneself." Unlike Shoemaker, we do not regard this as a tautology. On the contrary, it can be subjected to empirical investigation. Our main thesis is: awareness that mental states are instantiated does not entail awareness that said states are instantiated in self. Unlike most critics of Shoemaker, for the sake of argument, we grant

\footnotetext{
${ }^{26}$ Ibid., p. 273.

${ }^{27}$ Shoemaker, First-Person Perspective, p. 31.

${ }^{28}$ Shoemaker, “Self-Knowledge and 'Inner Sense,' Lecture II,” p. 275.

${ }^{29}$ Shoemaker, "Introspection and Phenomenal Character," Philosophical Topics, xxviII, 2 (2001): 247-73; cf. Shoemaker, First-Person Perspective, p. 31.

${ }^{30}$ Shoemaker, “Self-Knowledge and 'Inner Sense,' Lecture II,” p. 289. Also see p. 275.
} 
that most of his views are correct. Even so, we argue that genuine counter-examples to IEM exist.

II. IEM AND BODILY SENSATIONS: SOMATOPARAPHRENIA

Somatoparaphrenia is a syndrome that is characterized by the sense of profound estrangement from parts of one's body. ${ }^{31}$ It is typically found in patients who have suffered extensive right-hemisphere lesions (usually vascular). ${ }^{32}$ Lesions in the temporoparietal junction are a common neural correlate of somatoparaphrenia, but deep cortical regions (for example, the posterior insula) and subcortical regions (for example, the basal ganglia) are also sometimes implicated. ${ }^{33}$

Somatoparaphrenia is also closely associated with proprioceptive impairment and often (not always) co-morbid with hemispatial neglect. Patients feel that a contralesional limb, most frequently the hand, seems not to belong to them; indeed, it often seems to belong to someone in particular, not uncommonly an acquaintance. ${ }^{34}$ The sense of disownership can be so vivid that even after recovery patients continue to describe the estrangement in factive, not metaphoric, language. ${ }^{35}$

Baier and Karnath assessed the frequency of somatoparaphrenia's occurrence. ${ }^{36}$ They recently examined 79 , consecutively admitted, acute stroke patients with right brain damage. They found that 11 experienced estrangement: five exhibited asomatognosia, and six were afflicted with somatoparaphrenia. Of the six, two attributed ownership of the limb to their wives, three to their examining physicians, and one to a patient sharing the same room.

Somatoparaphenia is occasionally accompanied not only by hemispatial neglect, but also by tactile extinction (the loss of conscious

${ }^{31}$ Giuseppe Vallar and Roberta Ronchi, "Somatoparaphrenia: A Body Delusion. A Review of the Neuropsychological Literature," Experimental Brain Research, CxcII, 3 (2009): 533-51.

${ }^{32}$ For an exceptional case, see Rogerio Beato et al., "Transitory Somatoparaphrenia Associated with a Left Frontoparietal Meningioma," Journal of Neurology, ccLviI, 7 ( July 2010): 1208-10. For competing explanations of apparent lateralization, see Gabriella Bottini et al., "Productive Symptoms in Right Brain Damage," Current Opinion in Neurology, XXII, 6 (December 2009): 589-98, at p. 591.

${ }^{33}$ Vallar and Ronchi, op. cit., p. 548.

${ }^{34}$ Instances characterized just by the sense of limb disownership are referred to as asomatognosia; instances wherein limb ownership is attributed to someone else-some specific person-are referred to as somatoparaphrenia. The two are anatomically distinct. See Todd Feinberg et al., "The Neuroanatomy of Asomatognosia and Somatoparaphrenia," Journal of Neurology, Neurosurgery and Psychiatry, LXxxI, 3 (2010): 276-81.

${ }^{35}$ Peter Halligan et al., "Unilateral Somatoparaphrenia after Right Hemisphere Stroke: A Case Description," Cortex, xxxi, 1 (March 1995): 173-82.

${ }^{36}$ Bernhard Baier and Hans-Otto Karnath, "Tight Link Between Our Sense of Limb Ownership and Self-Awareness of Actions," Stroke: Journal of the American Heart Association, XXXix, 2 (2008): 486-88. 
tactile perception) in the estranged body part. Moro et al. demonstrated (for two cases) that merely by changing the position of the hands-moving the left hand across the midline of the body, over to the right-hand side-tactile sensation could be recovered. ${ }^{37}$ Even though tactile sensation could be so readily recovered, the sense of limb disownership was unchanged.

As regards our challenge to IEM, the most relevant case has been described by Bottini et al. ${ }^{38}$ A woman ("FB") reported that her left hand belonged to her niece and that she, FB, felt no tactile sensations there. In FB's case the lesion was subcortical, involving the basal ganglia, white matter underlying the insula, as well as other areas. But, importantly, the primary somatosensory area-which is critical to processing tactile sensation-was preserved. As Bottini et al. record: "F.B.'s spared ability to perceive tactile stimuli, provided that these were referred to someone else's body, was evidently based on the survival of some elementary somatosensory cortical functions." ${ }^{39}$

In a series of controlled tests, FB, while blindfolded, was advised that the examiner would touch her left hand; next, the examiner would in fact touch the dorsal surface of FB's hand. Whenever this was done, FB said that she could feel no tactile sensations. When advised that the examiner was about to touch her niece's hand, however, upon being touched FB reported feeling tactile sensation. Here we begin to see the relevance of FB's case to IEM.

It should be borne in mind that $\mathrm{FB}$ was in all other aspects cognitively sound. ${ }^{40}$ Moreover, in order to ensure that these tests would be reliable, catch trials-wherein FB was led to expect touches that were not forthcoming-were used. These trials were evenly distributed across three verbal warnings-I am going to touch your right hand, your left hand, and your niece's hand-and were administered in four sessions, two on one day, two on the next. It is of paramount importance to note that in not even one of 36 catch trials, nine each per session, did FB respond incorrectly. ${ }^{41}$ In other words, when advised that she (or her "niece") would be touched, if no contact was made, FB always reported "no," no contact had been made.

\footnotetext{
${ }^{37}$ Valentine Moro et al., "Changes in Spatial Position of Hands Modify Tactile Extinction but not Disownership of Contralesional Hand in Two Right Brain-Damaged Patients," Neurocase, x, 6 (2004): 437-43.

${ }^{38}$ Gabriella Bottini et al., "Feeling Touches in Someone Else's Hand," NeuroReport, XIII, 11 (2002): 249-52.

${ }^{39}$ Italics added by the authors. Bottini et al., op. cit., p. 251.

${ }^{40}$ According to the clinical report, FB was "fully oriented in time and space and did not show any other sign of mental deterioration on the Mini Mental State Examination (score: 26/31)." See ibid.

${ }^{41}$ Ibid., Table 1.
} 
As we begin examining IEM in light of this case, let us assume, for the sake of argument, that Shoemaker's central theses are largely correct. WST is true; both OPM and BPM, false. Moreover, self-as-subject is indeed distinct from self-as-object.

But even if we grant to Shoemaker his principal theses, we are left with an explanatory puzzle: why is it that when FB is expecting to be touched (on the left hand), she feels nothing, whereas when she expects that her niece will be touched there, she is able to report tactile sensation? Why, despite the experimental controls in place (for example, blindfold and catch trials), is she able to judge that "her niece" has been touched? Typically, to say (a) "I am going to touch your arm," implies (b) "I am going to touch you." It would be nonsensical to say (a) without implying (b). Likewise, when the doctor says, "I am going to touch your niece's hand," she implies, "I am going to touch your niece." The concern here is not where the sensation will be felt, but who will feel the sensation. Pace the prototypical situations that motivate the Wittgenstein-Shoemaker intuition-it is not absurd to inquire as to who is the subject of experience.

Let us divide the experiment into two parts: FB expecting that she will be touched is Part 1. FB expecting that her niece will be touched is Part 2. FB's case should be regarded as directly relevant to IEM because she has been primed by the doctor to introspect. We argue that in Part 2 FB is misrepresenting her tactile sensation as belonging to someone else. It is not the case that FB is misrepresenting the location of a sensation, as, for example, the base-runner does if he first represents his own leg as bleeding and then discovers that the bleeding leg is attached to the catcher with whom he collided. Instead, in Part 2, from FB's first-person perspective, when introspecting on that tactile sensation she misrepresents herself, such that she is not the owner of the sensation. In short, FB commits an error through misidentification regarding just who is the subject of the sensation. ${ }^{42}$

\footnotetext{
${ }^{42}$ One might still worry that FB's error concerns the location, not the subject of experience. For example, one possible characterization of FB's Part 2 is "I feel the sensation in my niece's hand." One could then argue that the subject of experience is not misrepresented. We should not assume, however, that this spare description can do full justice to the perplexing phenomenology. One problem is that it implies that $\mathrm{FB}$, in feeling the sensation, regards "her niece's hand" from a third-person point of view. Thus, it cannot fully capture the complex pathology. Why? Not only is the clinician baffled by the experimental results, FB too is baffled by her own paradoxical experiences (ibid., p. 251). Both FB's experience and her relation to "her niece's hand" are first-personal, introspective. An appropriate characterization, therefore, must also capture the perplexity from the first-person perspective. A more scrupulous reconstruction of this pathological experience would be: "I am introspectively aware of my niece's sensation." Under this reconstruction, the subject of experience, or the ownership of sensation, can be misrepresented.
} 
To repeat, we can concur with many of Shoemaker's central theses: (1) For every mental state there must be a subject who experiences it. Moreover, for the sake of argument, we can agree with Shoemaker's WST. Thus: (2) Every mental state is in principle available to introspection. And we think Shoemaker would be obliged to concede that FB can only have the experience of a tactile sensation in Part 2 by means of introspection.

Although Shoemaker does not explicitly adopt a position concerning the ownership of sensation, a natural interpretation of his views would be as follows. (1) and (2) conjoined suggest: (3) Every mental state is experienced by the one who is currently introspecting that state. ${ }^{43}$ The position is made explicit by Coliva, ${ }^{44}$ who takes herself to be "vindicating" Shoemaker's claim that "in being aware that one feels pain one is, tautologically, aware, not simply that the attribute feels pain is instantiated, but that it is instantiated in oneself." 45

We have formulated (1)-(3) in a way that fully accommodates Shoemaker's views. Our argument is that (1)-(3) do not provide sufficient ground to establish IEM. Proponents of IEM fail to take into account that (1)-(3) do not imply: (4) Every mental state is, from the first-person point of view, represented as experienced by the one who is introspecting the state. It is (4) that is needed for IEM to hold. FB's case is a counter-example to IEM because (4) is not true of those cases for which FB is introspectively aware of tactile sensation in Part 2. Although the attribute feels sensation is instantiated from the first-person point of view, it is not the case that the tactile sensation is instantiated in self. FB does not represent it in that way. The two instantiations are not tautologically linked. For IEM to be true, (4) must hold necessarily. But it does not hold with strict necessity; hence, IEM fails.

It is then empirically possible for a subject, while introspecting a mental state (and thereby knowing that someone is undergoing that state), to be in error with regard to who is experiencing that particular mental state. Admittedly, this is counterintuitive. The

\footnotetext{
${ }^{43}$ Shoemaker does, however, imply this position. See "Self-Reference and SelfAwareness," pp. 559-60, 565-67. We could articulate (3) such that it even more completely reflects Shoemaker's preferred mode of expressing his position by adding two clauses: (a) introspective awareness of phenomenal character occurs "if the subject reflects," and (b) it is just such introspective awareness that enables us to render judgments of the sort under consideration here, such as "I feel pain" (or, as applied to this case, "I feel a tactile sensation"). The relevant passages from Shoemaker are quoted above: the citation for (a) is indicated in fn. 29 and for (b) in fn. 16. But neither (a) nor (b) is critical to our argument.

${ }^{44}$ Coliva, "Thought Insertion," pp. 28-29.

${ }^{45}$ Shoemaker, "Self-Reference and Self-Awareness," pp. 563-64.
} 
Wittgenstein-Shoemaker intuition-it is absurd to inquire of the person who introspects and reports a toothache whether it is indeed that person who has the ache-strikes all of us as correct. But empirical inquiry has ways of upsetting the apple cart: it would by no means be absurd to ask of FB whether it is she who has the tactile sensations, even though it is she who produces the introspectively based report.

An important contrast here calls for explanation. We have a fact and a foil, ${ }^{46}$ the contrast between the two parts of FB's case. In Part 1 , when FB is primed to introspect on what she experiences, she reports nothing; in Part 2, when she is primed to introspect on what her niece experiences, she reports tactile sensation.

To ignore this difference would be to ignore a significant explanatory problem. Because Parts 1 and 2 have similar histories, it is possible to ask sensible contrastive questions that enable us to elicit causal differences. ${ }^{47}$ This possibility is not permitted by IEM. The essential difference between the two parts is whether FB represents herself as the subject of the mental state. This issue, concerning first-person representation of just who the subject is, we refer to as mental ownership.

One might worry that FB merely reports feeling the sensation, when in fact she does not feel anything. But had there been no actual sensations on this series of tests, the reports would not have been made. First, recall that in FB's case the lesion was subcortical; her somatosensory cortex was preserved. So it is not surprising that she retained the capacity for experiencing tactile sensations (provided that these were referred to someone else's body). Second, FB's performance on catch trials was perfect. Included among the catch trials were instances in which she was told that her niece's hand was going to be touched, when in fact it was not touched. In these trials she never once made a false report-neither on the first nor the second day of the experiments. Third, other standard procedures were in place to monitor FB's sustained attention and reliability of response: FB's hand was touched in a randomized, fixed sequence, which was repeated in four sessions on two separate days. Because she was blindfolded and because of the other controls that were in place, she could only have given an accurate report had she actually experienced the sensation of being touched.

Moreover, imaging studies of self-referential processing show that there is no reason to suspect that problems pertaining to mental

\footnotetext{
${ }^{46}$ See Peter Lipton, "Contrastive Explanation," in David-Hillel Ruben, ed., Explanation (New York: Oxford, 1993), pp. 207-27.

${ }^{47}$ Ibid., pp. 217-19.
} 
ownership typically impair tactile processing. Northoff et al.'s analysis of many and varied studies that engage the "feeling of mineness" 48 indicates that these experiences are subsumed by a set of commonly activated regions within the cortical midline structure (CMS), regions that do not include the somatosensory cortex.$^{49}$ More specifically, as regards somatoparaphrenia, Feinberg et al., in a detailed study of 13 patients who had been examined using brain-imaging techniques within one week of acute hospitalization, identified a pattern of lesions distinctive of those who exhibited its clearest symptoms: repeated, refractory expressions of the conviction that their limbs belonged to someone else. ${ }^{50}$ In this study, the region found to be most distinctive was not the somatosensory cortex; rather, it was the orbitomedial frontal cortex. ${ }^{51}$ The claim here is not that any one region of the brain plays an exclusive, causal role in the etiology of somatoparaphrenia. The claim is that there is no empirical reason to suppose that what underlies the distinctive phenomenology of somatoparaphreia necessarily involves incapacitation of areas critical to somatosensory processing. ${ }^{52}$

The only remaining reason to suspect that FB actually did not experience the sensations is the worry that her case is analogous to blindsight. In the case of numbsense-also referred to as "blindtouch"although subjects lack conscious tactile experience, they are to some degree capable of nonconsciously processing tactile information. ${ }^{53}$

\footnotetext{
${ }^{48}$ Georg Northoff et al., "Self-Referential Processing in Our Brain-A Meta-Analysis of Imaging Studies on the Self," NeuroImage, xxxi, 1 (May 2006): 440-57. In characterizing the "feeling of mineness" the authors say that "the self we consider here is an experiential self that mediates ownership of experience." See p. 441.

${ }^{49}$ Concerning the role of the CMS, Northoff et al. say, "Taken together, our results suggest that self-referential processing is mediated by cortical midline structures....We conclude that self-referential processing in CMS constitutes the core of our self and is critical for elaborating experiential feelings of self, uniting several distinct concepts evident in current neuroscience." See p. 440; also see pp. 448-49. As regards the relation between CMS and sensory processing, they report: "Our review of neuroimaging studies reveals a set of commonly activated regions, within the extended CMS, during self-related tasks using a diverse set of sensory modalities. Activation in CMS must therefore be considered independent of the sensory mode within which the self-related stimuli were presented. Such sensory independence of neural activity in CMS can be observed in all domains." See p. 449.

${ }^{50}$ Feinberg et al., op. cit.

51 "The orbitofrontal lesion was critical in the development of somatoparaphrenia versus simple asomatognosia." See ibid., pp. 279-80.

${ }^{52}$ Cf. many of the cases reviewed by Vallar and Ronchi, op. cit., Table 1, pp. 536-37.

${ }^{53}$ See Jacques Palliard et al., "Localization without Content: A Tactile Analogue of 'Blindsight'," Archives of Neurology, xL, 9 (September 1983): 548-51; Alberto Gallace and Charles Spence, "The Cognitive and Neural Correlates of 'Tactile Consciousness': A Multisensory Perspective," Consciousness and Cognition, XVII, 1 (2008): 370-407; and Yves Rossetti et al., "Implicit Body Representations in Action," in Helena De Preester and Veroniek Knockaert, eds., Body Image and Body Schema (Philadelphia: John Benjamins, 2005), pp. 111-25.
} 
In other words, perhaps FB was informationally sensitive to being touched but not experientially sensitive to being touched.

However, FB's case could not have been an instance of numbsense. For one thing, well-studied cases of numbsense involve damage to the primary somatosensory areas, very much unlike the case of FB. More importantly, in cases of numbsense the ability to make verbal report is lost. The reason given for ascribing numbsense is that the patients are able to point, with a moderate degree of accuracy, to the place where they were touched. In other words, by analogy to blindsight, their success at guessing based on nonconscious information is indicated by pointing, not by verbal report. FB's case is clearly not like this, since her capacity for verbal report is well preserved.

In conclusion, it seems that we are not immune in the way that IEM indicates. FB's introspections give rise to puzzling responses that are not compatible with IEM. Shoemaker's critical mistake might have been to infer from "what can happen as a matter of course," to what must necessarily be true of introspection and mental states. ${ }^{54}$

III. IEM AND THE SENSE OF AGENCY: BODY SWAP ILLUSION

The case against IEM can be made in multiple ways. In the previous section we dealt with bodily sensations. Here we show that similar problems can arise for the sense of agency concerning mental ownership.

Cognitive neuroscientists have been investigating whether specially designed experiments can induce in healthy subjects certain illusions pertinent to bodily self-consciousness. For example, in the case of the "Rubber Hand Illusion" it has been shown that ordinary people can experience an artificial hand as their own. ${ }^{55}$ In these experiments, investigators primarily have been interested in the ownership of body parts and various phenomena that involve self-as-object rather than self-as-subject. In at least some of these experimental cases, however, issues relevant to IEM and self-as-subject are implicated. Most noteworthy among these is the "Body Swap Illusion."

In this case the illusory experience of owning a body that belongs to someone else is induced in healthy subjects. Although some among the neuroscientists who discovered the illusion are concerned only with body ownership, we argue that some of their experiments actually involve ownership of mental states. In the particular case described below, subjects can misrepresent themselves as experiencing someone else's experiences. After describing the experiment, we explain how it violates IEM.

\footnotetext{
${ }^{54}$ Shoemaker, “Self-Knowledge and 'Inner Sense,' Lecture II,” p. 273.

${ }^{55}$ Matthew Botvinick and Jonathan Cohen, "Rubber Hands 'Feel' Touch that Eyes See," Nature, CCCXci (February 19, 1998): 756.
} 
The Body Swap Illusion was first demonstrated in a series of experiments conducted by Petkova and Ehrsson. ${ }^{56}$ In one setting (their Experiment 5), two persons were involved: experimenter and subject. The experimenter wore a helmet outfitted with two closed-circuit television (CCTV) cameras, which transmit signals to a specific place. By positioning the cameras thus, the scenes they registered presented the experimenter's viewpoint. Wearing a set of head-mounted displays (HMDs), the subject stood face to face with the experimenter. The subject's HMDs were connected to the two CCTV cameras on the experimenter's head such that the images from the CCTV cameras played on the HMDs. The effect of this set-up was that the subject, adopting the experimenter's perspective, visually perceived himself rather than the experimenter. ${ }^{57}$ The subject could see his own body from the shoulders to slightly above the knees. Both experimenter and subject were instructed to extend their right hands and then take hold, as if to shake. During the course of the experiment the two were instructed to squeeze one another's hands repeatedly, each time for two minutes. In the illusion condition, they squeezed in a synchronous manner; in the control condition, they squeezed asynchronously, alternating, the experimenter responding to the subject semi-randomly. ${ }^{58}$

Twenty subjects participated in this experiment, and each was interviewed immediately afterwards. The authors claim that the experiment "demonstrated that this set-up evoked a vivid illusion that the experimenter's arm was the participant's own arm and that the participants could sense their entire body just behind this arm. ${ }^{59}$ To obtain more objective, quantifiable data, the scientists incorporated an anxiety-inducing threat into the experimental design (a knife above the wrist to suggest cutting of the hand) and measured each subject's skin conductance response (SCR). They reported that they "observed significantly stronger skin conductance responses when the knife was moved near the experimenter's wrist than when it was moved towards the participant's own hand in the synchronous condition." 60

This experiment has significant implications for IEM. Note that in describing the participants' phenomenology, the authors say, "after the experiment, several of the participants spontaneously remarked...'I

\footnotetext{
${ }^{56}$ Valeria Petkova and Henrik Ehrsson, "If I Were You: Perceptual Illusion of Body Swapping," PloS One, III, 12 (December 2008): 1-9.

${ }^{57}$ Recall that one of Shoemaker's three prototypical examples of introspection is "I see a canary." See "Self-Reference and Self-Awareness," p. 557.

${ }^{58}$ Petkova and Ehrsson, op. cit., p. 4, Figure 6.

${ }^{59}$ Ibid., p. 5.

${ }^{60}$ Ibid., Figure 7.
} 
was shaking hands with myself!" 61 Although the subjects "could clearly recognize themselves and distinguish between their own arm and the arm of the experimenter," this illusion is so robust that "a participant can face his or her biological body and shake hands with it without breaking the illusion." ${ }^{2}$

How should this aberrant experience be understood? The most natural way to characterize the subjects' phenomenology is with respect to agency. When they experience the illusion of shaking hands with themselves, their experiences involve misrepresentation of action awareness - that is, the misrepresentation concerns "who" shakes their hands. This poses a problem for Shoemaker's IEM.

From the subjects' first-person point of view, the handshaking experience involves the awareness that I am the agent of this action. This recently has been called "agentive experience" or "agentive selfawareness"-I experience myself as someone who is doing something. ${ }^{63}$ What is distinctive about the Body Swap Illusion is that the subjects' agentive experience is mistaken. Although it was really the experimenter who was shaking their hands, the subjects misrepresented themselves as the agent of the action. ${ }^{64}$

To see how this creates a problem for Shoemaker's IEM as regards the case in question, we can agree with Shoemaker on each of the following: (1) For every agentive experience there must be a subject who experiences it. (2) Every agentive experience is in principle available to introspection. (3) Every agentive experience is experienced by the one who is currently introspecting it. The crucial point, however, is that (1)-(3) together do not imply: (4) Every agentive experience is, from the first-person point of view, correctly represented as experienced by the one who is introspecting it. Without (4) the ground upon which IEM stands is shaken.

Recall that one of Shoemaker's prototypical examples of self-assubject is "I am waving my arm." According to IEM, it cannot happen

${ }^{61}$ Ibid., p. 5.

${ }^{62}$ Ibid., p. 1.

${ }^{63}$ Tim Bayne provides a clear example of agentive experience: "It's your first day as a waiter/waitress, and you are pouring water into a glass from a jug. As you pour the water, you experience yourself as an agent. You experience yourself as someone who is doing something, rather than someone to whom things are merely happening." See Bayne, op. cit., p. 3. Also see Bayne and Elisabeth Pacherie, "Narrators and Comparators: The Architecture of Self-Awareness," Synthese, cvix, 3 (December 2007): 475-91.

${ }^{64}$ Bodily sensations might play a contributing role: light pressure, intensity, duration, and location on the hand, at the points where the hand is squeezed, can all be experienced. But the illusion-"I was shaking hands with myself"-primarily involves action awareness. Also, as we have argued in section II, IEM can be violated in the case of bodily sensations. 
that I am mistaken in saying "I am waving my arm" because although I do know of someone that is waving his arm, I am mistaken in thinking that person to be myself. I am necessarily aware that I am, myself, waving my arm. Mutatis mutandis for handshaking. This too clearly involves agentive experience. But as the body swap case shows, having an experience of handshaking does not guarantee that the agentive experience cannot be misrepresented. The mode of representation matters. Here, while in the illusory state, I am introspectively aware of the shaking hands, but I misattribute agency. I commit an error that violates IEM.

In the case of somatoparaphrenia, a subject violates IEM because she experiences a mental state in virtue of having represented that state as belonging to her niece. In the case of body swap, subjects violate IEM because they represent themselves as agents when plainly they are not. In both cases IEM is violated. Introspective awareness that a mental state is instantiated, pace Shoemaker, does not prevent us from error as regards mental ownership.

\section{RESPONSE TO POSSIBLE CRITICISMS}

In this section we consider three possible objections. The first concerns the relationship between conscious experience and reportability. The second concerns whether IEM should be regarded as a conceptual truth, and the third concerns an alleged distinction between agency and ownership.

First, the reason FB's case is particularly troubling for IEM is that it consists of two parts which reveal an explanatory contrast. In Part 1, when told that she will be touched, FB does not feel the sensation; yet, in Part 2, when told that her niece will be touched, she feels the sensation. The contrast exhibited here provides strong support for the claim that the self-as-subject of the relevant mental state is misrepresented in Part 2. Since FB felt the tactile sensation in Part 2, why didn't she feel it in Part 1? The only difference between Parts 1 and 2 concerns how the subject, from the first-person perspective, represents with regard to who is to be touched.

To salvage IEM, one might consider an alternative interpretation of her responses. Perhaps FB actually felt the sensation in Part I but, due to her pathologies, just could not report them. Were this so, the critical issue posed by this case might turn on the ability of FB to report tactile phenomenology, not the phenomenology itself. Proponents of IEM then could argue that IEM remains unchallenged because it does not presuppose a necessary connection between reportability and phenomenology. They could argue that FB felt the sensations both in Part 1 and Part 2, so it did not really matter whom the doctor said would be touched. It was just that FB failed to report it in Part 1. 
Successful defense of IEM, however, requires that this strategy not remain mere speculation. There must be some reason to suggest that it accurately describes what transpired in FB's case. But no wellmotivated reason suggests itself. On the contrary, there is good reason to think our interpretation of FB's case is accurate. Once again, recall that in order to ensure the reliability of FB's reports, the doctors conducted several catch trials that were evenly distributed across three different prompts: your right hand, your left hand, and your niece's hand. When untouched, FB never reported any sensation. When her right hand was touched, she always, unerringly, reported sensation. When her left hand was touched, she never reported sensation. But when her "niece's" hand was touched, she recovered tactile sensation. There is simply no evidence to suggest that reportability was a problem for her.

A second possible criticism is related to Campbell's interpretation of schizophrenia. ${ }^{65}$ Campbell takes IEM to be a datum in need of explanation. ${ }^{66}$ Indeed, he acknowledges, in accord with Wittgenstein and Shoemaker, that people take for granted the absurdity of asking, "Someone has a headache, but is it me?" Nevertheless, he does suggest that "there is some structure in our ordinary notion of the ownership of a thought which we might not otherwise have suspected." ${ }^{67}$

Coliva criticizes Campbell's interpretation of schizophrenia, and it is her defense of IEM that might abet those who would argue against our position. ${ }^{68}$ Here the concern is just what constitutes mental ownership. We should first emphasize that we do not agree with the entirety of Campbell's argument-neither is IEM a datum, nor is the WittgensteinShoemaker intuition veracious. What we do share with Campbell is the contention that ownership, as it pertains to conscious experience, is more complex than typically is acknowledged.

Responding to Campbell concerning the ownership of mental states, Coliva contends, "If a subject is introspectively aware of pain, this just means that she is feeling pain...it is a matter of conceptual truth that if a subject is introspectively aware of a certain mental state, then she herself is having it and, therefore, that mental state is her own." ${ }^{69}$ She emphasizes that, as a matter of conceptual truth, introspective

\footnotetext{
${ }^{65}$ Campbell, "Schizophrenia, the Space of Reasons, and Thinking as a Motor Process," The Monist, LxxxiI, 4 (October 1999): 609-25.

${ }^{66}$ Campbell, "Immunity to Error through Misidentification and the Meaning of a Referring Term," pp. 91-94; Campbell, "The Ownership of Thoughts," Philosophy, Psychiatry and Psychology, Ix, 1 (March 2002): 35-39.

${ }^{67}$ Campbell, "Schizophrenia," p. 610.

${ }^{68}$ Coliva, "Thought Insertion."

${ }^{69}$ Ibid., pp. 28, 29. Original essay not italicized.
} 
awareness of a mental state guarantees that one is the owner of said state. In developing her position she contends that other than introspective awareness, there simply is no independent criterion for what is to count as ownership of a conscious state. She regards this as a "vindication" of Shoemaker's treatment of IEM as a tautology. ${ }^{70}$

But Coliva's view cannot save IEM. To see why, for the sake of argument, let us agree that there really are no independent criteria. The problem then would be that lack of independent criteria would by no means imply that mental ownership cannot be misrepresented. The key statements (1)-(3), as discussed in the previous sections, can be reformulated as follows: (1) Every mental state belongs to a subject. (2) Every mental state is in principle available to introspection. (3) Every mental state belongs to the one who is currently introspecting that state. Notice that Coliva's view is fully accommodated by (3). As we have argued above, however, (1)-(3) together do not imply: (4) Every mental state is represented (from the first-person point of view) as belonging to the one who is introspecting the state. Coliva's objection fails because she neglects (4).

Furthermore, it is not clear that there are no independent criteria for determining mental ownership. Recall what transpires in the case of FB: when advised that she would be touched, she felt nothing. When advised that her niece would be touched, she felt tactile sensations. If we regard IEM as a tautology, if we believe that introspective awareness guarantees mental ownership, then we arbitrarily dismiss the possibility of discovering independent criteria. Such dismissal would be tantamount to begging the question. What has been discovered in the cases of somatoparaphrenia and the Body Swap Illusion is that first-person representation of the ownership of mental states does not comport well with what might seem to be logically necessary or conceptually guaranteed.

FB recovers sensation because she has been cued not to represent the touch as an experience of her own, but as an experience that belongs to her niece. In other words, how the subject represents the experience provides an independent criterion for determining mental ownership. There is no question as to whether or not it is FB who is providing a report based on introspection. So there is no denying that information concerning the tactile sensation is available to FB. But, from the first-person perspective, this is not the end of the story. Ownership of mental states is a more complex phenomenon than the received view of IEM allows.

\footnotetext{
${ }^{70}$ Shoemaker, "Self-Reference and Self-Awareness," pp. 563-64.
} 
To the self-as-subject, from the first-person perspective, it matters just how the relationship between self and sensation is represented. Call to mind that one of Shoemaker's projects has been to elucidate "the distinctive way mental states present themselves to the subjects whose states they are." ${ }^{71}$ What we have found is evidence that the distinctive way mental states present themselves to subjects varies and that, for one form of representation, ownership is contentious. It seems we have cases for which it would be by no means idle or absurd to inquire as to whether the experiences of which a person is introspectively aware belong to that person.

A third possible objection pertains to Gallagher's distinction between agency and ownership. ${ }^{72}$ He employs this distinction to deny that schizophrenic thought insertion causes problems for IEM, because he believes there is no doubt as to just where, experientially, these thoughts are. The patient might well be sincere in expressing the feeling that he is not the author of these thoughts, but that is not to deny that these thoughts occur within his stream of consciousness. "His judgment that it is he who is being subjected to these thoughts is immune to error through misidentification, even if he is completely wrong about who is causing his thoughts." ${ }^{\prime 73}$ In short, although the patient disclaims authorship, he does not deny experiencing the thought. Even in schizophrenia, there remains a nontrivial sense in which the inserted thoughts belong to the patient. Accordingly, in view of the fact that the relevant error in the Body Swap Illusion concerns agentive experience, one might try to argue that Gallagher's distinction applies here as well.

There are several reasons why this defense of Shoemaker's IEM fails. (i) For those subjects who feel that they are shaking hands with themselves during the illusion, it would still be reasonable to ask Wittgenstein-Shoemaker questions: is it you who is having the experience of squeezing your own hand? Is it you who is shaking hands with yourself? Arguably the most compelling intuition that motivates IEM is that questions of this type are absurd. But here they are not absurd. This very fact-that these questions can be well motivatedindicates that IEM does not enjoy the kind of modal force claimed by Shoemaker.

(ii) Admitting misrepresentation of agentive experience is already detrimental to Shoemaker's IEM. Again, one of Shoemaker's prototypical expressions of self-as-subject is "I am waving my arm." As is

\footnotetext{
${ }^{71}$ Shoemaker, First-Person Perspective.

${ }^{72}$ Gallagher, op. cit.

${ }^{73}$ Ibid., p. 231.
} 
the case with "I am in pain," "I am waving my arm" enjoys an absolute immunity. Unlike "I am in pain," though, here we have a clear instance of agency. Shaking hands, just like waving, implies agency. In other words, Shoemaker's elucidation of IEM would still be assailable.

Recall Shoemaker's formal articulation of his claim: for a statement " $a$ is $\Phi$ " to be erroneous through misidentification relative to the term " $a$ " is to allow for the following possibility: "the speaker knows some particular thing to be $\Phi$, but makes the mistake of asserting ' $a$ is $\Phi$ ' because, and only because, he mistakenly thinks that the thing he knows to be $\Phi$ is what ' $a$ ' refers to." But for IEM statements, mistakes of this type are not possible: whenever I say, "I am shaking hands," it cannot be the case that I am mistaken in thinking that the person who is shaking my hand is me. It cannot be the case that I have erroneously identified myself as the person who is shaking my own hand. But that is precisely what happens in the Body Swap Illusion.

(iii) Gallagher argues that the distinction he discerns in schizophrenic thought insertion is sufficient to rescue IEM. But schizophrenia is not analogous to the Body Swap Illusion. First, in the case of body swap the error does not concern a lack of agentive experience; instead, it involves the erroneous attribution of agency to oneself. In the illusory state, one takes credit for more-not lessthan one is capable of. Violation of Shoemaker's IEM in this instance is not due to denial of agency.

Second, in describing the schizophrenic's attribution of agency, Gallagher observes, "with respect to agency, he is in a position to make only statements in which he uses the first person pronoun as object-and in such cases the immunity principle is not at stake, and therefore cannot be violated." "In other words, Gallagher's view is that because schizophrenics lack agentive experience, they can only regard the "author" of inserted thoughts as object. Schizophrenia, then, is conspicuously different from the case of body swap. In the latter case, the subject misattributes agency to self. That is to say, the agent is regarded not as object, but as subject. Since here the agent is a self-as-subject, Gallagher's distinction cannot safeguard IEM.

(iv) Finally, and decisively, this strategy simply would not work for the case of somatoparaphrenia. No parallel argument drawing upon Gallagher's distinction can be made. The somatoparaphrenia case involves no action on the subject's part whatsoever.

In previous sections, we argued that adequate explanation of somatoparaphrenia and the Body Swap Illusion requires recognition

${ }^{74} \mathrm{Ibid}$. Italics added by the authors. 
that the ownership of mental states can be misrepresented. In this section, we have responded to what we regard as the strongest defenses of IEM and contend that they are not successful. We therefore conclude that the best explanation of the relevant cases reveals that IEM, rather than being a conceptual truth, is an empirical hypothesis, open to verification or refutation. Indeed, this hypothesis is confronted by substantive counterexamples. ${ }^{75}$

\section{CONCLUSION}

We have, for the sake of argument, adhered to the distinction between self-as-subject and self-as-object. According to Shoemaker, "absolute" immunity applies to self-attribution of mental states only as regards the former. What we have discovered is that, even when concerned exclusively with self-as-subject, we are not necessarily immune to error in the way that Shoemaker claims.

According to Shoemaker, introspective awareness that one feels pain tautologically implies both that (a) the attribute feel(s) pain is instantiated and that (b) it is instantiated in oneself. But the cases examined here reveal that (a) and (b) are just contingently connected. It is important to distinguish between those states which are instantiated in someone and those states-of which one is introspectively aware-that are represented as belonging to oneself. Mental states can be introspectively available to a subject without being represented as owned by the subject.

Accordingly, even when considering self-as-subject, we are not immune to error through misidentification relative to the first-person pronoun. Misidentification is possible because we can represent the ownership of mental states variously. Because the ownership of mental states is surprisingly complex there is no guarantee that subjects will not misidentify the subject of experience.

\footnotetext{
${ }^{75}$ Thus far we have not discussed perception of the external world-the third of Shoemaker's prototypical cases. But, in personal communication, Roland Zahn has described a recent case which suggests that even here IEM can be violated. (Zahn is a Clinical Research Fellow with the Neuroscience and Aphasia Research Unit at the University of Manchester.) The patient was suffering from right inferior temporal hypometabolism, problems pertaining to the supply of or ability to metabolize glucose. Multiple clinical interviews designed to elicit the patient's phenomenology consistently revealed that visual experience required a two-step process: upon first becoming aware of an object it was not immediately obvious that the object was being seen by self. In order to recognize a visual experience as belonging to self it was necessary to take a second step. This step involved relating what was being seen to who was seeing it. Caution is warranted in interpreting this case, for although the condition persisted for at least two months, all information derives from clinical or diagnostic assessments. No experimental protocols were employed. But if Zahn's description is accurate, then Shoemaker's IEM fails for all three of the prototypical cases.
} 
Others who have considered the type of cases treated herein have given most attention to the disownership of body parts. But from the first-person perspective, the question as to whether one owns a body part is distinct from questions concerning the ownership of mental states. For example, in the Body Swap Illusion, subjects are able to distinguish their own arm from the arm of the experimenter. Nevertheless, the illusion that one is shaking one's own hand persists. Ownership of body parts does not necessarily imply ownership of mental states. By allowing for this possibility we are able to account for what otherwise would be a wholly baffling phenomenon: I can recognize the hand extended in front of me as belonging to someone else while simultaneously feeling that I am shaking my own hand.

What does it matter if the ownership of mental states is complex in the ways that we indicate? Although we do not separately develop the issue here, one implication seems to be that first-person mental states are not identification-free in the way that Shoemaker claims. And since identification-freedom is a linchpin for many of Shoemaker's views concerning mental states and introspection, its loss would betoken significant consequences for other aspects of his views on self-consciousness.

Most philosophers agree that the what of conscious experience can be misrepresented, but that the who can be misrepresented continues to strike many as absurd. Shoemaker's IEM is an articulation of this robust intuition, the intuition that is well expressed by Wittgenstein's rhetorical question. But once these intuitions are clearly articulated, they are better regarded as hypotheses. Otherwise they can be found to arrest growth in understanding. Failure to allow for possible misrepresentation of the subject of experience leads to failure to ask important questions in empirical contexts.

Shoemaker's articulation of IEM as a conceptual truth was an attempt to say what is distinctive about self-consciousness. As we have argued, however, IEM is neither datum, nor tautology, nor conceptual truth. It is a hypothesis. By showing that mental ownership can be misrepresented, we have exposed IEM's vulnerability. Progress in understanding self-consciousness will require further inquiry into the phenomenon of mental ownership.

TIMOTHY LANE

National Chengchi University

CALEB LIANG ${ }^{76}$

National Taiwan University

\footnotetext{
${ }^{76}$ The order of authorship was determined arbitrarily; this manuscript is completely collaborative.
} 